\title{
A ABORDAGEM FENOMENOLÓGICA SHUTZIANA E SUA APLICAÇÃO NA COMPREENSÃo DA PRÁTICA PEDAGÓGICA DOS ANOS FINAIS DO ENSINO FUNDAMENTAL
}

\author{
THE SHUTZIAN PHENOMENOLOGICAL APPROACH AND ITS APPLICATION IN \\ UNDERSTANDING THE PEDAGOGICAL PRACTICE OF THE FINAL YEARS OF \\ FUNDAMENTAL EDUCATION
}

\author{
EL ENFOQUE FENOMENOLÓGICO SHUTZIANO Y SU APLICACIÓN EN LA \\ COMPRENSIÓN DE LA PRÁCTICA PEDAGÓGICA DE LOS ÚLTIMOS AÑOS DE LA \\ EDUCACIÓN FUNDAMENTAL
}

\author{
Isamary Roberta Ferreira Cézar (iD \\ Universidade Estadual do Sudoeste da Bahia - Brasil \\ Nilma Margarida de Castro Crusoé \\ Universidade Estadual do Sudoeste da Bahia - Brasil
}

\begin{abstract}
Resumo: Esse artigo destaca o aspecto metodológico da pesquisa realizada no mestrado, objetiva apresentar as contribuições da fenomenologia sociológica shutziana e sua aplicação para a compreensão da prática pedagógica, como produtora de sentidos, sustentada nos conceitos de motivação, experiência e sentido, deste modo, trata-se aqui de exibir a coerência interna entre o objeto e a abordagem metodológica escolhida. De natureza qualitativa, a pesquisa foi desenvolvida com professores da rede pública municipal, por meio de entrevista semiestruturada decodificadas pela análise de conteúdo. Dessa forma, foram produzidas metanarrativas, material necessário para compreensão dos sentidos atribuídos por professores às práticas pedagógicas que desenvolvem. Seguindo essa perspectiva, foi possível compreender sentidos de práticas pedagógicas atribuídos por professores, dos anos finais do ensino fundamental, como fenômenos atrelados ao contexto de suas interações sociais, em função de processos interpretativos por eles utilizados ao lidarem com as situações. A abordagem fenomenológica schutziana permitiu perspectivar a ação pedagógica como uma ação dotada de sentidos que ao serem revelados, via pesquisa, permitem enunciar diferentes configurações de práticas, marcadas por crenças e valores idiossincráticos, ainda que ali se incluam prescrições governamentais.
\end{abstract}

Palavras chave: Fenomenologia Sociológica Schutziana. Prática pedagógica. Ensino Fundamental.

\begin{abstract}
This article highlights the methodological aspect of the research carried out in the master's program. it is here to show the internal coherence between the object and the chosen methodological approach. Of a qualitative nature, the research was developed with teachers from the municipal public network, through semi-structured interviews decoded by content analysis. In this way, metanarratives were produced, material necessary for understanding the meanings attributed by teachers to the pedagogical practices they develop. Following this perspective, it was possible to understand the meanings of pedagogical practices attributed by teachers, from the final years of elementary school, as
\end{abstract}


phenomena linked to the context of their social interactions, due to the interpretive processes they use when dealing with situations. The Schutzian phenological approach allowed the perspective of pedagogical action as an action endowed with meanings that, when revealed, through research, allow the enunciation of different configurations of practices, marked by idiosyncratic beliefs and values, even though government prescriptions are included there.

Keywords: Schutzian Sociological Phenomenology. Pedagogical practice. Elementary School.

Resumen: Este artículo destaca el aspecto metodológico de la investigación realizada en el programa de maestría, con el objetivo de presentar los aportes de la fenomenología sociológica shutziana y su aplicación a la comprensión de la práctica pedagógica, como productora de significados, a partir de los conceptos de motivación, experiencia y sentido, por lo tanto, se trata de mostrar la coherencia interna entre el objeto y el enfoque metodológico elegido. De carácter cualitativo, la investigación se desarrolló con docentes de la red pública municipal, a través de entrevistas semiestructuradas decodificadas por análisis de contenido. De esta forma se elaboraron metanarrativas, material necesario para comprender los significados que los docentes atribuyen a las prácticas pedagógicas que desarrollan. Siguiendo esta perspectiva, fue posible comprender los significados de las prácticas pedagógicas atribuidas por los docentes, desde los últimos años de la escuela primaria, como fenómenos vinculados al contexto de sus interacciones sociales, debido a los procesos interpretativos que utilizan al enfrentarse a situaciones. El enfoque fenomenológico schutziano permitió la perspectiva de la acción pedagógica como una acción dotada de significados que, al ser revelados, a través de la investigación, permiten enunciar diferentes configuraciones de prácticas, marcadas por creencias y valores idiosincrásicos, aunque se incluyen prescripciones gubernamentales.

Palabras clave: Fenomenología sociológica schutziana. Práctica pedagógica. Enseñanza fundamental.

\section{Introdução}

Esse artigo é resultado de pesquisa de mestrado ${ }^{1}$ cujo interesse consistia em ouvir o que os professores tem a dizer sobre as práticas pedagógicas que realizam, entendendo-as como práticas produtoras de sentidos, o que nos provocou posicionar esse estudo na fenomenologia sociológica de Alfred Schutz (2012). Ressaltamos que, nos contornos desse artigo, iremos nos ater ao aspecto metodológico da pesquisa realizada, com o objetivo de apresentar a sua aplicação para a compreensão da prática pedagógica, dos anos finais do ensino fundamental, como produtora de sentidos, portanto, trata-se aqui de exibir a coerência interna entre o objeto e a abordagem metodológica escolhida. Sobre a pesquisa, buscamos, portanto, compreender sentidos de práticas pedagógicas nos anos finais do ensino fundamental, como sentidos compartilhados pelo grupo que compõe a escola. Sentido, nessa pesquisa, é tratado como sentido subjetivo atribuído pelos professores à sua ação. Ou seja, a ação pedagógica é dotada de sentidos que ao serem revelados, via pesquisa, permitem perspectivar diferentes

\footnotetext{
${ }^{1}$ Pesquisa de mestrado desenvolvida junto ao Programa de Pós-Graduação em Educação (PPGEd), da Universidade Estadual do Sudoeste da Bahia (UESB);
} 
configurações de práticas, marcadas por crenças e valores idiossincráticos, ainda que ali se incluam prescrições governamentais.

Esta pesquisa consente, então, uma imersão na prática pedagógica docente, com base nos sentidos de professor(a) — sujeitos basilares para materialização desse processo, pois marcam suas práticas de acordo com suas concepções epistêmicas, seus conhecimentos técnicos e suas idiossincrasias que se referem a "sedimentação de todas as experiências prévias do indivíduo, organizadas como uma posse [...] exclusiva, trata-se de algo que é dado a ele e somente a ele" (SCHUTZ, 2012, p. 85).

Nesse movimento, fez-se necessário conhecer sentidos sobre práticas pedagógicas atribuídos por professores dos anos finais do ensino fundamental e, contextualizá-los relacionando-os ao aporte fenomenológico, principalmente, por entendermos que, também a análise de dados é parte da metodologia. No percurso investigativo a escolha de um método e uma metodologia de investigação envolve um importante processo de fundamentação teóricometodológica, pois “confere os instrumentos necessários para a interrogação da real e adequada escolha das metodologias de investigação, e para que ultrapasse a mera visão do senso comum sobre os fenômenos" (AMADO, 2017, p. 19).

A escolha pela abordagem qualitativa fenomenológica se justifica por incidir sobre o universo de significados, motivos, aspirações, crenças, valores e atitudes, “[...] é de se desejar que as relações sociais possam ser analisadas em seus aspectos mais concretos e aprofundadas em seus significados mais essenciais" (MINAYO, 2010, p. 21-22). Logo, a proposta desta pesquisa é desenvolver estudos com base em sentidos/significados do fazer pedagógico e

[...] consiste numa pesquisa sistemática, sustentada em princípios teóricos (multiparadigmáticos) e em atitudes éticas, realizadas por indivíduos informados (teorética, metodológica e tecnicamente) e treinados para efeito; pesquisa tem como objetivo obter junto dos sujeitos a investigar (amostras não estatísticas, casos individuais e casos múltiplos) a informação e a compreensão (o sentido) de certos comportamentos, emoções, modos de ser, de estar e de pensar (modos de viver e construir a vida); trata-se de uma compreensão que se deve alcançar tendo em conta os contextos humanos (institucionais, sociais e culturais) [...] (AMADO, 2017, p.17).

Com o objetivo de compreender a pratica pedagógica, via apreensão de sentidos, como expressão do mundo interno das professoras, entende -se ser necessário o contato direto e interativo do pesquisador com o informante/objeto de estudo o que justificou a escolha da entrevista semiestruturada como instrumento para conhecer e contextualizar o fenômeno, traduzindo e anunciando os sentidos atribuídos ao mundo social, segundo a perspectiva dos informantes. O exercício nessa pesquisa foi então, o de preservar os lugar do pesquisador e do informante na relação de pesquisa ao intencionar que as experiências contextuais de práticas 
pedagógicas fossem traduzidas como uma narrativa, em primeira mão (tradução dos professores sobre a sua prática) e, de segunda mão (tradução dos sentidos dos professores sobre a sua prática), pela pesquisadora.

Para a compreensão dos sentidos ${ }^{2}$ de professoras sobre prática pedagógica nos anos finais do ensino fundamental nos apoiamos nos conceitos de sentido, experiência e motivação presentes na fenomenologia sociológica de Alfred Schutz, ao quais serão manipulados no item a seguir, em diálogo com o objeto de pesquisa.

\section{Sentido, experiência e motivação: possibilidades de leitura fenomenológica da pratica pedagógica nos anos finais do ensino fundamental}

Começamos por afirmar que a abordagem fenomenológica schutziana permite pensar a pratica pedagógica como produção de sentidos. Sentidos construídos na relação entre a consciência e o mundo. A consciência dirige-se para o mundo e nesse movimento intencional ela atribui sentido aos objetos do mundo. O sentido é a compreensão que a ação tem para o indivíduo que a executa, para o sujeito com quem interage e para quem o observa (SCHUTZ, 2012). Refere-se ao constructo das interações sociais, sendo modificados em função de processos interpretativos utilizados pelas pessoas ao lidar com as questões encontradas. A escola e o mundo social são espaços que compõem o mundo da vida das professoras, pois

[...] o mundo da vida constitui a esfera de todas as experiências, orientações e ações cotidianas, mediante as quais os indivíduos buscam realizar seus interesses e seus negócios a partir da manipulação de objetos, da interação com as pessoas, da elaboração de planos e da efetivação destes. (SCHUTZ, 2012, p. 25).

Entendemos que o espaço escolar é atravessado por crenças e valores compartilhados pelos professores e que orientam a sua ação pedagógica. Sob a perspectiva da investigação de Amado, Crusoé e Vaz-Rebelo (2017), o objetivo da fenomenologia social é compreender o que revelam as experiências vividas pelos indivíduos por meio de descrições feitas por ele mesmo. Para isso, "[...] a pesquisa deve buscar responder quais foram os motivos, as razões, a intencionalidade, que estiveram na base da ação total de tal ou tal pessoa [...]" (AMADO, CRUSOÉ \& VAZ-REBELO, 2017, p. 84). A nossa tarefa como pesquisadoras é entender a intencionalidade das ações, em face das experiências significativas dos informantes acerca do

\footnotetext{
${ }^{2}$ Na perspectiva Schutziana não há diferença entre sentido e significado. Trata-se dos conteúdos da experiência relacionados à subjetividade. "O significado de um ato do sujeito é um ato de atribuição de sentido por parte do próprio sujeito, e é sempre significado de intenção subjetiva" (SCHUTZ, 1974 apud CAPALBO, 2000 p. 294).
} 
fenômeno investigado - prática pedagógica. Suas experiências intersubjetivas e os motivos para esse ou aquele comportamento. Entender os "motivos para" e os "motivos porque". (SHUTZ, 2012).

Cada pessoa apreende o fenômeno de maneira individual, por isso, compreender o fenômeno depende das experiências vivenciadas pelo indivíduo no contexto de suas relações sociais. Desse modo, apropriamo-nos da fenomenologia de Schultz (2012) por se tratar de um estudo sociológico que analisa os fenômenos do ser no contexto suas interações sociais. Com o objetivo de descrever a estrutura da experiência vivida e os significados que ela possui para os sujeitos que a vivenciam, embasados pela fenomenologia social, descreveremos as unidades de sentidos dos indivíduos, acessados por meio da entrevista entendendo ali que

A consciência é sempre consciência de alguma coisa. As formas de consciência são vinculadas ao conteúdo de experiências. A experiência é a atenção 'voltada' para os objetos, sejam estes reais ou imaginários, materiais ou ideais; e todos esses objetos são 'intencionados'. Esse é um 'processo imanente a toda experiência'; o objeto é construído por um processo de apercepção mediante a síntese de diferentes 'perspectivas' a partir das quais o objeto é realmente visto ou lembrado de modo tipificado" (SCHULTZ, 2012, p. 16).

Acredita-se que esse aporte contribui para responder o mote que norteou o nosso trabalho: quais sentidos de práticas pedagógicas são atribuídos por professoras e professor dos anos finais do ensino fundamental e de que forma tais sentidos atravessam as suas práticas? $\mathrm{O}$ ponto de partida, é o sentido atribuído à própria experiência, o que sente e o que pensa sobre o que sente; momento em que a consciência percebe o fenômeno. Schutz (2012) busca na sociologia compreensiva de Weber ampliar o conceito de sentido na perspectiva de pensar o outro na ação social, construída na relação com o outro, e com isso, compreender a ação social como uma prática que comporta um agir com relação ao outro. Portanto, agir com sentido é fruto da expectativa em relação ao outro, percebida no comportamento do indivíduo. Entendemos a escola como um campo empírico riquíssimo para tal análise, pois como apresenta Schutz (2012), existem outros eu's ${ }^{3}$, que não apenas o eu consciência como anunciara Husserl, existem os eu's sociais, a exemplo da família, da igreja e da escola. (CRUSOÉ; SANTOS, 2020).

\footnotetext{
${ }^{3}$ Fruto das anotações realizadas nas aulas de Seminário de Pesquisa II, no Programa de Pós-Graduação em Educação (PPGEd) da Universidade Estadual do Sudoeste da Bahia (UESB), ministrada pela Prof. ${ }^{a}$ Nilma Margarida de Castro Crusoé.
} 
Sendo o eu consciência, a base para existência do mundo (realidade) fora dela; quem apreende essa realidade é a consciência e o mundo passa a existir no encontro entre a consciência (sujeito) e o mundo (realidade).

Como descreve Menezes; Crusoé (2019, p. 60), importa destacar

\begin{abstract}
Um outro ponto, e esse acompanha os paradigmas da investigação qualitativa, no caso específico desse trabalho a pesquisa fenomenológica, é o assento nos domínios da subjetividade tanto do pesquisador como do pesquisado. Sabese, por exemplo, que na técnica de Análise de Conteúdo, a codificação se assenta na interpretação do pesquisador e, nesse caso, é preciso investir em processos de controle via movimento de adequação e readequação dos instrumentos de produção e análise de dados, configurando-se numa pesquisa em processo, pois, ao lidar com subjetividades tem-se o desafio de apreendêlas objetivamente.
\end{abstract}

Relembrar as experiências vividas, subjetivas e pensar sobre elas faz parte do processo de pesquisa na perspectiva fenomenológica, entender o sentido da conduta com um olhar de totalidade e unidade, atribuir significados ao que se faz e extrapolar o pensamento objetivo, é a intenção desse estudo na escolha de uma pesquisa de natureza qualitativa, inspirada no método fenomenológico.

Enquanto pesquisadoras partimos da apreciação do todo para a unidade como o objetivo de entender o fenômeno, por meio do ponto de referência dos informantes (docentes) envolvidos plenamente nele. Por isso, do ponto de vista da apropriação, esses informantes se manifestam acerca de significados atribuídos a sua ação pedagógica. O objetivo deste método é a descrição, o detalhamento exaustivo do mundo da vida, do agir com sentido dos professores.

A fenomenologia, para além da descrição da experiência humana, propõe compreender e interpretar, o que o sujeito - professor(a) - experimenta em relação ao fenômeno — prática pedagógica - e de que modo compreende/interpreta essa ação. A procura pela produção de sentido intenciona conhecer como os informantes da pesquisa cunham realidades sobre a prática pedagógica desenvolvida e o quanto estas experiências funcionam como instrumentos de subjetivação, isto é, a narrativa dessas professoras e desse professor apresentará como se percebem e se posicionam no contexto escolar da prática pedagógica.

Os atores sociais, de acordo Schutz (1971 apud MINAYO, 2010, p. 147), ganham a maior parte do seu conhecimento em face do seu espectro de mundo e em relação aos seus semelhantes, no decorrer da sua vida. São essas as experiências que compõem sua subjetividade. Ao desenvolver a prática pedagógica, nessa compreensão, percebemos que ela envolve um mundo de sentidos/significados enredados na intersubjetividade docente, de modo que as motivações e intenções são influenciadas por esses elementos. Logo, a realidade é constituída pelas experiências intersubjetivas, em uma construção social. 
Nessa perspectiva, com a abordagem qualitativa, segundo Amado (2017, p. 43), "procura-se o que, na realidade, faz sentido e como faz sentido para os sujeitos investigados [...] procuram-se os fenômenos tal como são percebidos e manifestados pela linguagem [...]". A aproximação aos entrevistados, no percurso, é uma característica possibilitada pela natureza da pesquisa, o que torna possível analisar, via narrativa, sentidos de prática pedagógica atribuídos por docentes.

A fenomenologia consente uma apreensão do mundo da vida por quem vive as experiências, considerando a intersubjetividade. É possível entender a singularidade de cada um, demonstrada em suas aproximações e diferenças por intermédio da linguagem utilizada para descrever e caracterizar a realidade que vivencia. Vale destacar a relevância dessa perspectiva teórico-metodológica para esse estudo, pois permite trazer ao campo acadêmico a voz dos docentes, atores educacionais envolvidos cotidianamente com a ambiência escolar.

Para produção dos dados, realizamos a pesquisa de campo que, para Gil (2002, p. 53 54), "procura o aprofundamento das questões propostas e seu planejamento apresenta flexibilidade podendo ocorrer mesmo que seus objetivos sejam reformulados ao longo da pesquisa". Tal entendimento contribuiu para compreender o que pensam as docentes sobre o que fazem, trata-se da "prática como produção de sentidos"4 (CRUSOÉ; SANTOS, 2020). Para tanto, nessa pesquisa, a entrevista semiestruturada se apresenta como instrumento de pesquisa importante.

Isso porque importa, para essa pesquisa, conhecer a história das(o) informantes e suas experiências formativas, quais são seus motivos para ser professor(a), e como definem educação, escola, currículo, conhecimento escolar e prática pedagógica; conceitos que permeiam o dia a dia do docente. Nos interessa ouvir sobre como enxergam as relações entremeadas pelo contexto escolar: ensino-aprendizagem; saber-conhecimento escolar; educadora-saber-conhecimento escolar; educadora-aluno; educadora-educadora e educadoraequipe pedagógica, educadora-família e as estratégias utilizadas/escolhidas para orientar a ação na escola e na sala de aula.

Contextualizar essa realidade implica escutar acerca das crenças, dos valores e das atitudes (CRUSOÉ, 2014) que permeiam o fazer docente, e, portanto, que sentidos atribuem à prática pedagógica desenvolvida na escola, nos anos finais do ensino fundamental. Como

\footnotetext{
${ }^{4}$ A expressão "prática como produção de sentidos" tem relação com a fenomenologia sociológica de Alfred Schutz, comporta valores, crenças e marca o agir no mundo da vida cotidiana. Tal expressão vem sendo desenvolvida por CRUSOÉ, Nilma Margarida de Castro e consta no artigo por CRUSOÉ, Nilma Margarida de Castro Crusoé; SANTOS, Edmilson Menezes. Fenomenologia sociológica de Alfred Schutz: contribuições para a investigação qualitativa em prática educativa. Rev. Tempos Espaços Educ. v.13, n. 32, e-13274, jan./dez.2020 e nas dissertações de mestrado orientadas por Crusoé, no Programa de Pós-Graduação em Educação (PPGEd), da Universidade Estadual do Sudoeste da Bahia (UESB).
} 
afirma a professora Vogel (2020, p. 18), "é a simplicidade que emoldura a memória emocional, que nos constitui como gente e, para reativá-la ao nível de consciência, é necessário nos perguntar: pelo que o nosso coração "suspira"?"

A entrevista semiestruturada é necessária nesse estudo, pois "permite certa liberdade de expressão, pois apoia-se em uma relativa flexibilidade" (GIL, 2002) que proporciona, segundo Laville e Dionne (1999), um contato maior entre o entrevistado e o entrevistador, que colhe informações com o intuito de obter, além da compreensão de sua realidade social, o conhecimento de suas motivações pessoais, bem como a exploração dos conhecimentos pessoais dos entrevistados. Assim, foram produzidas metanarrativas, material necessário para compreensão dos sentidos atribuídos às práticas pedagógicas.

Conforme a fenomenologia, o indivíduo no mundo da vida sofre influências do contexto, pois está interrelacionado de modo que o conhecimento gerado dessa vivência é diverso, relaciona-se com a bagagem biográfica e reflexiva das pessoas. (SCHUTZ, 1971 apud MINAYO 2010, p.146). Ainda segundo Minayo (2010), essa diferença é valiosa para quem trabalha com pesquisa qualitativa, com destaque para as entrevistas, pois os informantes apresentarão detalhes diversos que permitirão um aprofundamento em narrativas sobre a mesma situação, porque são descritas por atores diferentes, mesmo quando compartilham a mesma realidade.

A entrevista se justifica como um instrumento essencial para alcance dos dados nessa pesquisa, porque possibilita compreender o contexto (conhecer a história do informante e suas motivações, suas crenças e valores e de que modo permeiam sua prática), o significado (as concepções, conceitos e definições acerca dos elementos que constituem seu ofício) e o processo (como enxergam as relações estabelecidas no dia a dia) sentido por quem vivencia o fenômeno em pesquisa.

Chega-se o tempo de tratar os dados levantados para alcance dos significados/sentidos atribuídos. A descrição e análise das informações compreendeu leituras extenuantes para categorização do fenômeno. O objetivo nesse processo é a familiaridade com a experiência vivida e relatada pelas professoras e pelo professor: destaca-se os elementos das descrições, agrupa-se em unidades, na procura por respostas para as questões que circundam o objetivo da pesquisa.

Para tratamento e análise dos dados, as entrevistas foram decodificadas por meio de análise de conteúdo, essa técnica foi considerada na perspectiva de compreender criticamente o sentido das informações construídas pelos participantes dessa investigação. Em função disso, buscamos identificar dimensões, categorias e relações na pesquisa a ser desenvolvida. Afinal, 
são muitas as possibilidades de análise diante da diversidade de significados de uma mensagem quando relacionadas ao contexto em que a comunicação acontece. A compreensão do conjunto, para essa técnica, é fundante para o entendimento do conteúdo revelado no texto.

Para alcançar as significações constituídas no texto além dos ditos pelo(as) professor(as), do conteúdo explícito, importa considerar as relações existentes no contexto, o destinatário e as formas transmissão e de codificação da mensagem. Portanto, para toda análise de conteúdo, o contexto em que se analisam os dados deve ser aberto, conhecido e reconstruído pela pesquisadora. Nessa reconstrução, há limites, não é admissível a inclusão de informações, embora, não haja limites lógicos para delimitar o contexto da análise, pois todas as condições coexistem (mundo da vida e da consciência). A pesquisa prevê objetivos para a investigação, o caminho de análise foi elaborado anteriormente, quando se escolheu o roteiro da entrevista semiestruturada.

Depois de realizadas as entrevistas, é elementar seguir as etapas da técnica de análise do conteúdo. De acordo com Crusoé (2014), o passo inicial do processo de interpretação dos dados é a escuta atenta e cuidadosa de toda a conversa com as(o) professoras(o), realizando transcrição na íntegra das falas, pausas, pontuações e reações. Essa sistematização contribuiu para compreensão das ações, assim como para considerar, nesse trabalho, os conceitos de sentido, de motivação e de experiência do(as) informantes, sempre apoiadas na orientação teórico-metodológica proposta para esse trabalho. A escuta exaustiva das entrevistas e o registro dessas com o vocabulário próprio do(as) professor(as) é essencial para a disposição metódica das falas, o desenvolvimento do texto e, necessariamente, para a qualidade da pesquisa, pois ela torna possível retornar o que foi dito e como foi dito. Movimento que torna a pesquisa um organismo vivo e pulsante.

O segundo passo é a organização sistemática dos textos, permitida pela leitura vertical de cada entrevista, em que se retira os indicadores da fala, processo essencial que permitiu identificar as categorias e subcategorias, e possibilitou estruturar os temas a serem trabalhados na análise, com isso, conseguimos apreender o significado individual. (CRUSOÉ, 2014).

Posteriormente, os temas revelados na leitura vertical foram organizados em uma lista lógica. Tínhamos, portanto, ao esboçar o mapa conceitual e o estruturar, a matriz inicial. Escolhemos a frase, como unidade de sentido para análise dessas entrevistas (CRUSOÉ, 2014). Ao fazermos uso dos critérios definidos pela análise de conteúdo, estruturamos, nesse processo, nossa matriz conceitual, manifestando a compreensão de cada categoria, a saber: 
- Tornar-se professor: essa categoria intenciona conhecer a trajetória de formação, ao considerar o que indicam as motivações iniciais e as experiências formativas no caminho que leva a prática pedagógica. Entender, portanto, com quais professores estamos falando.

- Pensamento da Professor: objetiva entender o que inspira a prática pedagógica dos professores informantes, apresentar as concepções que orientam o conhecimento desses acerca de educação, currículo, escola e os princípios que norteiam essas concepções, por fim, apresentar as características da prática pedagógica que realizam.

- Prática pedagógica: descrever os sentidos que os professores atribuem à prática pedagógica, delineando as expectativas, as construções e os desafios encontrados no fazer pedagógico, no cotidiano da prática.

\section{Sentidos de Prática pedagógica: uma leitura fenomenológica}

A prática pedagógica é a nossa realidade mesmo [...], por entre risos, Ester continua por dizer que, [...] ela deve partir sim do Currículo, [...] de toda fundamentação teórica, só que aí partindo desse currículo e chegando na sala de aula, exercer a sua prática pedagógica. Rute destaca a necessidade de se [...] ter esse olhar mais carinhoso para a prática, isso envolve, segundo Ana, o [...] planejamento, que é a base da prática. [...] Perceber como tá sendo percebido, ter essa sensibilidade também, de como tá sendo recebido. Maria, afirma, em seus quase 30 anos de profissão, que hoje [...] a prática tá mais difícil, [...] como você chegar no aluno, [...] tá se tornando mais difícil.

Essas falas formam a primeira etapa dessa conversa, porque para além de provocarem uma reflexão, traduzem o cenário da Prática Pedagógica no contexto escolar. Ela está envolta e ao mesmo tempo tomada por um todo que a compõe e a forma: legislação, fundamentação, exercício, olhar sobre, planejamento, bom senso, processo e resultado; e é desenvolvida pelo professor em uma conjuntura que abarca além de si próprio, os estudantes, gestão escolar, a família, os colegas professores e outros profissionais que trabalham na escola.

A prática ficou mais difícil, porque [...] o menino em qualquer época, não é a pandemia, [...] eu não sei se ele não valoriza, ou ele não quer, mudou os interesses, Maria continua a descrever o que na compreensão dela tem tornado a prática [...] mais difícil... parece que não agrada, mesmo que você leve alguma coisa diferente, o aluno não valoriza muito o aprender, Rute concorda quando diz: eu acho que o obstáculo maior hoje, [...] é fazer com que o menino queira aprender, e apresenta em seu discurso um dado relevante para essa conversa, [...] alguns pais banalizam o ensino. [...] Preocupam se o menino vai para a escola porque tem que receber 
o bolsa família, mas não preocupam se o filho tá aprendendo, [...] banaliza um pouco para o menino também.

Diante essas informações, percebemos um reflexo da atitude da família no comportamento do aluno, da banalização do processo de educação escolar. Partimos da declaração de Schutz (2012), em que a consciência se associa às experiências do sujeito, uma vez que a consciência é intencional, podemos extrair as unidades de significações que os sujeitos atribuem ao mundo diante das suas experiências de vida.

O aluno tem que ter vontade de aprender ou então você tem que despertar o prazer nele de aprender. Essa fala de Maria revela que para ocorrer a aprendizagem, é preciso que haja uma disponibilidade do estudante para aprender. Isso envolve escuta, problematização, elaboração de dúvidas, discussão, trata-se de um caminho metodológico, mas a disposição de fazer o percurso é necessária.

Com base no aporte teórico desse trabalho, o discurso acima reafirma que os sujeitos vivenciam a realidade do mundo da vida em intersubjetividade, e que mediante o ato de rememoração das experiências, os sentidos sobre a prática pedagógica fluem e são informados em acordo com a sua importância, pois as professoras, ao olharem para as suas experiências significativas, transmitem o que realmente as estruturou e estrutura (AMADO, 2017; SCHUTZ, 2012).

O planejamento é importantíssimo. Se você tem um bom planejamento, você consegue desenvolver sua prática de forma mais simples. Para Ana, um planejamento cuidadoso simplifica a ação docente no dia a dia, mas acrescenta, [...] no planejamento, analisar direitinho o nível de escolaridade dos meninos. Essa fala apresenta um sentido significativo para essa discussão, para um bom planejamento é necessário conhecer o estudante, mais especificamente, o nível de escolaridade. É possível entender explicitamente diante do exemplo por ela citado: [...] ano passado eu peguei sexto ano, os meninos chegam sem saber ler, sem saber fazer as quatro operações básicas, não sabem escrever, [...] com essa dificuldade mesmo de base.

Como Ana, consideramos o planejamento fundante no processo da prática e, concordamos com o sentido que ela atribui nesse discurso, de que o planejamento nasce de uma ação reflexiva da ação docente e será efetivo se for revisto e refeito quando necessário, mas isso só acontecerá ao entender que a aprendizagem do estudante é o centro do trabalho do professor. Caso contrário, [...] se você não presta atenção, [...] você vai ficar ensinando para as paredes (ANA, 2020).

Para Schutz (2012), é por meio do trabalho que a pessoa se comunica com as outras e se realiza em sua totalidade. As preocupações narradas pelos professores demonstram que as 
alterações do trabalho no contexto atual, são exigências que solicitam do profissional outras habilidades para lidar com o alcance das tarefas destinadas.

Ali (sala de aula) a gente vai encontrar várias pessoas, uma diversidade muito grande, muitos anseios. [...] Tempos de aprendizagem diferentes, então essa prática apesar de ela nascer desse Currículo, ela nasce do conhecimento teórico que a gente (professor) traz (ESTER, 2020, grifos nossos). Essa fala de Ester diz muito sobre a sala de aula e sobre a prática pedagógica, bem como sobre as relações reveladas nesse contexto. Oferta lugar à diversidade, ao tempo de aprendizagem, ao currículo e ao conhecimento do professor, aspectos que quando se interpenetram resvalam na prática pedagógica - como ação pensada por um profissional intelectual, coerente com a realidade conjuntural e com características singulares, porque desenvolvida por cada professor. Bem distante do modus operandi definido pela BNCC.

Em concordância com Ester, o informante Manoel expressa: com cada aluno isso vai acontecer de um jeito, às vezes quando briguei com um aluno, eu estabeleci uma relação com ele. Por que ninguém nunca o repreendeu, ninguém nunca deu limite para ele. O sentido revelado nessa fala do professor, é que ao dar importância ao que o estudante estava fazendo, o lugar da disciplina, da reorientação, assume um lugar significativo na aprendizagem, a ação dele é notada, portanto, ele existe e é percebido. Manoel acrescenta, [...] o afeto é fio condutor desse processo de elaboração de sentidos, e destaca, [...] o afeto distanciado, porque o aluno não pode entrar na sua vida pessoal. Na concepção do professor Manoel, trata-se do [...] afeto pedagógico, [...] estabelecer uma relação com o aluno - confie em mim e eu possa ensiná-lo. Maria define que esse movimento [...] precisa ser uma relação de empatia.

Segundo Minayo (2010), a fenomenologia sociológica sublinha que os sujeitos vivenciam suas experiências no mundo da vida no encontro face a face em intersubjetividade com o outro. Isso é observado nos discursos acima. Isso é percebido quando os professores buscam apoio na experiência profissional, para encontrar formas de lidar com os desafios da prática docente. Também comprova, de modo geral, que os sentidos sobre as experiências formativas traduzem uma prática que está emaranhada por experiências pedagógicas que se materializam, fundamentalmente, em intersubjetividade com o outro, para o aprendizado dos estudantes.

Essa intersubjetividade com o outro, ampara-se no experienciar - afetos, aspirações, valores - em interação social, em que os sentidos se constroem, como afirma Schutz (2012),

[...] o mundo social no qual o homem nasce e no qual ele precisa encontrar o seu caminho é experienciado por ele como uma estreita rede de relações sociais, de sistema de signos e símbolos, com sua estrutura particular de significados (p. 92). 
Ester compactua com essa concepção do estudante, isso é revelado em sua fala: [...] eu gosto de ser muito sincera com eles em relação a todo processo [...] como eles estão sendo avaliados, mostrar [...] nosso processo durante o trimestre, o quê que nós iremos trabalhar, [...] ser o mais clara possível, essa estratégia pensada e usada pela professora parte da sua subjetividade, e é baseada em seus valores, mas se justifica em uma escolha pedagógica intencional. Ela então afirma, [...] quando ele (aluno) percebe sinceridade no processo mesmo aqueles mais rebeldes, a gente ganha a atenção, o crédito.

Maria retoma a conversa sobre valores e amplia a pauta [...] em sala de aula, o aluno não precisa só daquele conteúdo, [...] eu sou evangélica e eu não deixo de falar de família e de respeito, [...] porque os valores [...] estão deturpados, [...] falam muito palavrão, [...] são debochadas, [...] eu falo que tem tempo pra tudo. Essa fala nos lembra que, como a prática pedagógica agrega novas crenças e valores por meio da experiência, 'os outros eus' que nos formam — igreja, amigos —, também acrescenta crenças e valores que levamos para o mundo da vida (SCHUTZ, 2012; CRUSOÉ; SANTOS, 2020).

Assertivamente, Ester, em suas palavras, diz, então o respeito ao ser humano precisa ser cultivado e trabalhado na escola, [...] os valores, estão se perdendo, por mais que a gente busque manter a questão do respeito ao outro, às diferenças. O respeito é o valor mais citado nos discursos, em alguns momentos, até como resposta a um outro valor, na sequência da narrativa de Ester, entendemos o porquê: [...] a gente vive uma contradição, há a necessidade de respeitar sim, de conviver com aquilo que é diferente, seja na religião, seja no gênero, seja no quer for, do que é diferente.

Somente quando a ação vira ato, torna-se possível apreciar o "porque”, o motivo. É no momento de ação concluída que a pessoa pode se tornar observadora de si mesma (SCHUTZ, 2012). Isso revela a consciência da professora acerca da existência do outro, de um outro inteiro, diverso, diferente e com o direito à educação pública, gratuita e de qualidade.

Constatamos, na análise das subcategorias que alimentam essa seção, que os professores entendem a sala de aula como um espaço-tempo de interação social e cultural, motivado pelo enredamento da prática pedagógica. Esses professores ainda consideram que nesse espaçotempo, o professor tem o compromisso de trabalhar o conhecimento científico e formar para os valores que resvalam na vida pessoal e social. A intenção é contribuir para a transformação, atravessada pela formação integral do indivíduo.

A minha prática? [...] a partir do conhecimento que eu tenho do meu aluno, é tentar colocar nele mesmo a importância [...] que a educação tem e pode de mudar a vida dele [...] a partir da necessidade que ele tem ... nas minhas atividades, no meu discurso da sala de aula, 
[...] tentar chamar esse aluno para a importância. Ester revela, nessa fala, que ela compreende a educação como fenômeno de transformação social, por isso, as estratégias pedagógicas pensadas por ela tem um objetivo, uma intenção - que o estudante entenda o poder do processo educativo para a vida dele, e, um ponto de partida - a partir da necessidade que ele tem. Inferimos que as estratégias de práticas produzidas pelos professores, de forma subjetiva e muitas vezes coletiva, buscam, para além de atingir os objetivos traçados, superar desafios apresentados diante das relações que abarcam a vivência escolar.

Como estas estratégias estão configuradas nas práticas coloquiais de ensino, buscamos as encontrar atravessadas pelos discursos, que traduzem: distâncias e aproximações pedagógicas, dificuldades, conflitos, alternativas e estratégias. Esses aspectos evidenciam as características do ambiente educativo em que os professores dos Anos Finais do Ensino Fundamental atuam, especialmente, nos $6^{\circ}$ e $9^{\circ}$ anos, considerando o caráter de orientações primeiras e de terminalidade do segmento.

Nas palavras do professor de artes, Manoel, no sexto ano, ano passado eu fiz uma experiência [...] eu percebia, por exemplo, [...] eles ainda não têm coordenação fina. Essa é uma habilidade necessária para o ato de aprender, e, espera-se que tenha sido desenvolvida na educação infantil, quando chega nesse segmento com ela deficitária, sentimos na fala do professor que há um comprometimento com o processo. Acerca disso, Manoel prossegue, [...] tem celular, computador, [...] e quer que o aluno saiba escrever bem. [...] que ele consiga desenhar bem [...] mas, se ele está com o celular do lado o tempo todo.

$\mathrm{O}$ acesso e a disponibilidade à internet e aos recursos tecnológicos, nesse caminho, traz outros sentidos à prática pedagógica nesse contexto. O professor acrescenta, [...] você está ensinando coordenações diferentes e pedindo coisas diferentes para o estudante e ele no celular [...]. Há aqui um significativo sentido revelado, entre o que o professor compreende necessário fazer e o que interessa ao aluno realizar, o que repercute em um processo de frustração [...] ninguém consegue com a cara no computador, com aplicativo e clicando e clicando. [...] desenvolver habilidades necessárias. Nesta pesquisa, o suporte dos pressupostos metodológicos de Schultz (2012) possibilita um entendimento do mundo exterior e admite reconhecer e identificar os objetos, ou seja, interpretar o mundo em suas tipificações.

Para Maria, professora de língua portuguesa, os estudantes não chegam com uma prática de leitura muito boa, e você tem que ver tudo isso e ainda preocupada com aquelas classes gramaticais. Os sentidos revelados nesses discursos, comprovam uma informação bastante conhecida por todos nós que vivemos no chão da escola. É preciso desenvolver as 
habilidades primeiras que são de responsabilidade da escola, para que seja possível ensinar e aprender.

Em um outro momento nesse texto, a professora Ana apresentou em sua fala - acerca de outras dificuldades reais dos alunos do $6^{\circ}$ ano: de leitura, escrita e sob as quatro operações matemáticas fundamentais - o que denominou de nível de escolaridade e sinalizou a interferência e relevância disso na qualidade do planejamento, na perspectiva do avanço.

Diante dos exemplos narrados acima, entendemos que a realidade preocupa, afinal, a prática no $6^{\circ}$ ano tem sido um retrato de reparação ao que não foi feito no processo educativo até ali, por conta das dificuldades sinalizadas pela ausência das habilidades primeiras. O centro de interesses no campo da discussão e dos conhecimentos científicos não se modificam, não se aproximam da idade biológica e a educação escolar se torna desinteressante. Por isso, consideramos esse um elemento significativo que contribui para que o índice de reprovação nessa série seja o mais elevado e, por consequência, o de evasão no $7^{\circ}$ e $8^{\circ}$ anos, serem mais altos, deixando para o $9^{\circ}$, um número pequeno de alunos que não desistiram do processo de aprender pelo caminho.

O embasamento teórico-metodológico dessa pesquisa, incita-nos a entender os sentidos da experiência para a prática pedagógica, diante das narrativas acima, compreendemos que o conhecimento que formamos sobre as tipificações pode ser generalizado ou pode partir de um entendimento próprio que desenvolvemos acerca do objeto, em função do modo como vivenciamos as experiências. Sendo assim, “[...] o conhecimento dessas tipificações e de seu uso adequado é elemento inseparável da herança sociocultural transmitidas às crianças nascidas no grupo por seus pais e professores [...] ele é, portanto, socialmente derivado" (SCHUTZ, 2012, p. 133).

A professora Maria, narra algumas situações que necessitam intervenção cotidiana coletiva: (1) [...] "não estão fazendo o dever de casa” ou [...] "não estão retornando com as atividades". Nesse caso, são duas as estratégias utilizadas pela equipe e citadas por ela, o visto de crédito no caderno, [...] só vai ser validado depois que eu der o meu nome, minha rubrica [...] houve conclusão da tarefa. Essa fala revela o cuidado da professora em criar vínculos de compromisso com o estudante e com seu processo de aprender. A outra estratégia, para lidar com uma questão semelhante, [...] coloco no caderno do aluno, hoje ele não saiu muito bem. [...] a mãe assinar embaixo [...] ela viu isso aqui [...] Estratégia de falar com o pai... Essa opção pedagógica tomada por Maria, reflete a necessidade da escola de partilhar com a família o desenvolvimento do aluno. 
(2) [...] Os meninos então chegando no portão da escola, mas eles não entram no horário. O caminho da professora, nesse caso, é compartilhar a informação e a responsabilidade. Chego na direção e falo: [...] eu vi na porta da escola e os três não estão na sala, $[. .$.$] pergunto para o porteiro, o porteiro tem uma pista, a menina da merenda também$ viu, acaba que a gente descobre. Contar com a equipe, considerar que eles podem contribuir para lidar com as situações que envolvem todos, de forma significativa, [...] até que com professor, diretor, porteiro, menina da merenda, a gente descobre que realmente eles estavam, saíram para tomar refrigerante e voltaram dizendo que tinham chegado naquele horário. (3) [...] saem pra ir nesse banheiro e tomar água, ficam no pátio. A estratégia foi então institucionalizada. [...] Só saía com o crachá, para a gente saber onde o menino estava. [..] professor é observador.

Fica perceptível, por meio dessas falas da entrevistada, a necessidade de encarar os conflitos, produzindo algumas estratégias que compõem a prática pedagógica, de forma coletiva. Maria, então, explica como funciona na escola, a lida com os desafios como os exemplificados nas falas acima, [...] primeiro é com os pares, aquela inquietação [...] depois a gente descobre que os outros também estão tendo dificuldades [...] primeiro nos corredores, na sala dos professores, depois [...] encaminha para a coordenadora, [...] a diretora, [...] para depois virar uma reunião. Estratégias como essas, são consideradas coletivas porque se tornam práticas institucionalizadas no contexto da escola, como um acordo de conduta com todos os profissionais envolvidos na escola.

Os sentidos traduzidos pelas falas da professora Maria, nos informam que respostas satisfatórias, aos conflitos diários, são mais facilmente alcançadas mediante decisões coletivas, além de partilhar as responsabilidades. Conseguimos fazer uma relação com o conhecimento que o indivíduo constrói em intersubjetividade não se dá de forma mecânica, pois, em interação com o mundo, agimos sobre ele, logo, não vivemos de forma pacífica e completamente natural (SCHUTZ, 2012).

\section{Considerações finais}

A pesquisa teve como alicerce teórico-metodológico a Fenomenologia Sociológica de Alfred Schutz, sustentada nos conceitos de motivação, experiência e sentido. Seguindo essa perspectiva, foi possível compreender sentidos de práticas pedagógicas atribuídos por professores dos anos finais do ensino fundamental. 
Ao longo da investigação, apreendemos que os sentidos atribuídos envolvem a motivação inicial para a trajetória profissional, antes mesmo de dar início à carreira docente, por isso, essa compreensão requer considerar as experiências no percurso e sua constituição no contexto da formação, por meio das relações intersubjetivas.

Consideramos relevante acadêmica e socialmente investigar os sentidos que o(as) professor(as) atribuem à prática pedagógica — na perspectiva schutziana — especialmente por compreender que tais sentidos se estruturam e estão atravessados pelas experiências do professor no mundo da vida. Nesse sentido, a prática pedagógica passa a ser compreendida para além dos elementos vinculados à formação docente ou da prática social que exerce por meio dela.

Reflete-se, portanto, a intenção enquanto essa prática se materializa, demonstrando a relação vivida no dia a dia da escola, a qual está envolta por uma intersubjetividade que motiva, ampara e fundamenta a prática, por conseguinte, deriva em uma confluência de significados acerca da realidade. Entender o que representam estas experiências vivenciadas pelas(os) professoras(es), por meio do olhar reflexivo, permitem-nos abarcar o conhecimento que o sujeito constitui em sua intersubjetividade, o que se dá quando há interação com o outro.

Ao regressar o olhar com atitude retrospectiva e reflexiva às experiências de outrora, que se compuseram significativas, os informantes da pesquisa demonstraram que a realidade social tem sentidos para quem a vive, por isso, sentem-se confortáveis em expressar o seu entendimento sobre a realidade que os circundam. A fenomenologia, inspirada em Schutz, não interroga essa interpretação, mas intenciona compreender os seus sentidos.

Nessa perspectiva, entendemos que essa abordagem teórica-metodológica é potente e contributiva em pesquisas sobre Práticas Pedagógicas nos Anos Finais do Ensino Fundamental, pois colabora para se pensar e trazer para o espaço acadêmico uma análise que objetiva ouvir do professor acerca da prática que desenvolve. Importa pautar em nossas discussões acadêmicas os desafios imprevisíveis, mas reais, como o que temos vivido na atualidade. Desse modo, pensar um outro modelo de escola enquanto se pratica, ou ainda, pensar na estrutura educacional do mundo pós-pandemia do covid-19. Diante dos novos dados e feitos, cabe considerar o que diz o campo de pesquisa e os professores, de que é fundamental compreender e lidar com a realidade a que fomos expostos, isto é, de se relacionar com significado, mesmo estando isolados.

Fica claro, afinal, que por meio das relações, há uma rede de sentidos. Desse modo, ousamos dizer que a pesquisa movimenta um ineditismo, no que se refere à análise da prática pedagógica dos anos finais do ensino fundamental, em face dos sentidos sustentados pela 
fenomenologia sociológica de Alfred Schutz. Ela se alarga a outras possibilidades de análise, ao sinalizar a probabilidade de desdobrar a investigação pelo reconhecimento de novas estratégias de práticas, expandindo para a observação dessa prática pedagógica, com perspectivas em contribuir, de modo relevante, para os estudos em prática pedagógica no mundo pós-pandemia.

\section{REFERÊNCIAS}

AMADO, João, (org.). Manual de investigação qualitativa em educação. 3.ed. Coimbra: Imprensa da Universidade de Coimbra, 2017.

AMADO, João; COSTA, António Pedro; CRUSOÉ, Nilma. Procedimentos de análise de dados. In: AMADO, João (Coord.). Manual de investigação qualitativa em educação. Coimbra: Imprensa da Universidade de Coimbra, 2017.

AMADO, João; CRUSOÉ, Nilma; VAZ-REBELO, Piedade. Quadros analíticos da investigação qualitativa em educação. In: AMADO, João (Coord.). Manual de investigação qualitativa em educação. Coimbra: Imprensa da Universidade de Coimbra, 2017.

CRUSOÉ, Nilma Margarida de Castro Crusoé; SANTOS, Edmilson Menezes. Fenomenologia sociológica de Alfred Schutz: contribuições para a investigação qualitativa em prática educativa. Rev. Tempos Espaços Educ. v.13, n. 32, e-13274, jan./dez, 2020.

CRUSOÉ. Nilma Margarida de Castro. Prática pedagógica interdisciplinar na escola: sentidos atribuídos pelas professoras. 1. Ed Curitiba, PR: CRV, 2014.

GIL, Antônio C. Como elaborar projetos de pesquisa. São Paulo: Atlas, 2002.

LAVILLE, Christian e DIONNE, Jean. A Construção do Saber: manual de metodologia da pesquisa em ciências humanas. Porto Alegre: Artmed/Belo Horizonte: UFMG, 1999.

MENEZES, Edmilson \& CRUSOÉ, Nilma Margarida de. Fenomenologia Sociológica de Alfred Schutz: Contribuições para a investigação qualitativa em prática educativa. Congresso Ibero-Americano em Investigação Qualitativa. Atas CIAIQ 2019. Disponível em: https://proceedings.ciaiq.org/index.php/CIAIQ2019/issue/view/27. Acesso em 20 nov.2019.

MINAYO, M.C. de S. O desafio do conhecimento: Pesquisa Qualitativa em Saúde. (12a edição). São Paulo: Hucitec-Abrasco, 2010.

SHULTZ, A. Sobre fenomenologia e relações sociais. Edição e organização: Helmut T. R. Wagner. Tradução: Raquel Weiss. Petrópolis, RJ: Vozes, 2012.

VOGEL, Acedriana Vicente. Bananeira não dá pêra: e outras crônicas sobre educação. Curitiba, Editora Piá: 2020. 
SOBRE AS AUTORAS:

\section{Isamary Roberta Ferreira Cézar}

Mestre em educação, Universidade Estadual do Sudoeste da Bahia (UESB); Professora substituta do Instituto Federal do Norte de Minas Gerais, Salinas - Brasil; Coordenadora Pedagógica da rede privada na cidade de Vitória da Conquista, Bahia; Membro do Grupo de Estudos e Pesquisa em Praticas Curriculares e Educativas (GEPPCE), CNPq. Correio eletrônico: isamaryrobertaferreiracezar@gmail.com

iD https://orcid.org/0000-0001-8414-8085

\section{Nilma Margarida de Castro Crusoé}

Doutora em educação, pela Universidade Federal do Rio Grande do Norte (UFRN), com Estágio Doutoral na Universidade de Coimbra, PT. Professora Plena do Departamento de Filosofia e Ciências Humanas e do Programa de Pós-Graduação em Educação, da Universidade Estadual do Sudoeste da Bahia (UESB), Vitória da Conquista - Brasil. Líder do Grupo de Estudos e Pesquisa em Praticas Curriculares e Educativas (GEPPCE), CNPq. Correio eletrônico: nilma.crusoe@ uesb.edu.br

iD https://orcid.org/0000-0002-0610-8237 